\title{
Numerical simulations of hydropower station plane steel gate
}

\author{
Jinbo LIU $^{1, a}$, Hongming ZHANG ${ }^{1, b}$ \\ ${ }^{1}$ Department of Engineering Mechanics, Kunming University of Science and Technology, \\ Kunming,650500, China
}

aljb2015@126.com, bcorresponding author:hmzhang8888@126.com

Keywords: ecological gate; finite element; hydropower

\begin{abstract}
Plane steel gate is widely used in hydropower station. In this paper,by using the large-scale general software UGNX and ABAQUS, the ecological plugging gate model of a hydropower project and the model without hole for finite element is established. Considering the gate gravity, hydrostatic pressure, the stress and displacement of gate in two different models are analyzed, finally the cause of gate failure analysis, have important reference significance to similar engineering.
\end{abstract}

\section{Introduction}

A hydropower station is the seventh power station the Jinsha river middle reaches of the river cascade development of , located in the Dali bai minority autonomous prefecture of yunnan province. The hydropower station is given priority to with power generation, as well as soil and water conservation, shipping and tourism, and other functions. Engineering hub buildings is mainly composed of roller compacted concrete gravity dam, the river overflow table hole and the base hole, diversion tunnel, the right bank of underground powerhouse and the building such as switching station. The hydropower station plugging ecological drainage hole gate is flat steel gate, supported by a fixed wheel . Plane gate layout is compact, manufacturing more easily, safe and reliable use, convenient maintenance, widely used in all kinds of hydraulic structures and other occasions. So far, in all countries in the world the number of plane gate is adopted on engineering facilities are still in the lead. China's water conservancy project using one of the most earliest gate is plane gate, welding steel gate has been widely used at present, from the design, manufacture, installation and use and so on various aspects have reached world advanced level. The design water head is $93 \mathrm{~m}$. The material of the gate is Q345 and Q235. The constants of the material are shown in table 1.

table 1 the constants of the material

\begin{tabular}{|c|c|c|}
\hline Modulus of elasticity & Density & Poisson's ratio \\
\hline $206000 \mathrm{MPa}$ & $7.85 \times 10^{-9} \mathrm{t} / \mathrm{mm}^{3}$ & 0.3 \\
\hline
\end{tabular}

According to the steel gate design of water conservancy and hydropower engineering [1], the strength conditions of gate structure : $\sigma<[\sigma]^{\prime}=\mathrm{K}[\sigma]=0.9 \times[\sigma]$. Steel plate of Q345: if thickness less than or equal to $16 \mathrm{~mm},[\sigma]^{\prime}=0.9 \times 230=207 \mathrm{MPa}$; if thickness is greater than 16 to $25 \mathrm{~mm}$, $[\sigma]^{\prime}=0.9 \times 220=198 \mathrm{MPa}$; if thickness is greater than 25 to $36 \mathrm{~mm},[\sigma]^{\prime}=0.9 \times 205=184.5 \mathrm{MPa}$. The allowed equivalent stress for the panel: $\left[\sigma_{\mathrm{zh}}\right]^{\prime}=1.1 \times 1.4 \times[\sigma]=1.1 \times 1.4 \times 198=304.9 \mathrm{MPa}$. The stiffness conditions of main girder: $\mathrm{Y}_{\max }<\mathrm{L} / 750$. Steel of Q235: $[\sigma]^{\prime}=0.9 \times 160=144 \mathrm{MPa}$.

The stress distribution of the gate is very complex. The magnitude and direction of the stress are changing, Generally checking the strength of gate is according to the fourth strength theory[2]. In the report the Mises stress of each point is given. The benefits of given Mises stress is convenient to judge the strength of the gate, because Mises stress directly corresponds to the fourth strength theory. 


\section{Establishment of the model}

Steel gate is general constituted by the panel, beam, support and walk support etc [3]. In this paper to set up gate entity model adopts UGNX [4]. Then the solid model is imported to ABAQUS. The finite element model of gate is shown in Figure 1. And the finite element model of gate without hole is shown in Figure 2.

When static water retaining gate, constraints imposed on the fixed axle. Vertical constraints is imposed on the bottom panel.

Owing to the complicated and components in the model display to orange, can not be meshed directly. So at first the model will be divided into several simple parts. Then the structured grids or scanning grids were generated in each region. In this article, I use the scanning grid technology to hexahedral grid components, unit selects the second complete integral unit. The accuracy is much higher than linear unit [5].

\section{Calculate condition}

In this paper, the calculate condition is gate static water retaining conditions. The load is the water pressure and the self weight of the gate. When the water retaining head for $93 \mathrm{~m}$ calculate the deformation and stress distribution of the gate.

\section{Results and discussion}

93m head static water retaining conditions, the displacement of gate along the direction of flow is shown in figure 3. As can be seen from the graph, the displacement of both ends is minimum. The displacement of central is larger. The maximum displacement is $16.96 \mathrm{~mm}$, located in the beam grid of panel. From Figure 3 we can see, in 93m head water retaining conditions, the maximum displacement of the middle of bottom beam along the direction of flow is $(12.1-1.2)=10.9 \mathrm{~mm}$, greater than the allowable deflection of main beam $[\mathrm{f}]=\mathrm{L} / 750=7300 / 750=9.7 \mathrm{~mm}$. So the gate can not satisfy the stiffness requirements.In $93 \mathrm{~m}$ head water retaining conditions, Mises stress of gate is shown in Figure 4. As can be seen from the graph, the maximum stress location of gate is the web.Mises stress of gate bottom main beam webs is shown in figure 5. Figure 6 is the diagram of the range that Mises stress of bottom main beam web plates exceeds the allowable stress. The following is the results of the model without hole. $93 \mathrm{~m}$ head static water retaining conditions as the same, the displacement of gate along the direction of flow is shown in figure 7. As can be seen from the graph, the displacement of both ends is minimum. The displacement of central is larger. The maximum displacement is $11.30 \mathrm{~mm}$, located in the beam grid of panel. From Figure 7 we can see, in 93m head water retaining conditions, the maximum displacement of the middle of bottom beam along the direction of flow is $(7.4-0.3)=7.1 \mathrm{~mm}$, less than the allowable deflection of main beam $[\mathrm{f}]=\mathrm{L} / 750=7300 / 750=9.7 \mathrm{~mm}$. So the gate without hole can satisfy the stiffness requirements.Mises stress of gate is shown in Figure 8. As can be seen from the graph, the maximum stress location of gate is the web.Mises stress of gate bottom main beam webs is shown in figure 9 .

\section{Summary}

Can be seen from the graph, stress of gate main beam webs is larger. The maximum stress is located on the ends of bottom main beam web plates. The maximum Mises stress of gate bottom main beam webs is $751.3 \mathrm{MPa}$, larger than the allowable stress of 198MPa 279\%. The maximum Mises stress is far greater than the allowable stress here. As you can see from Figure 6 the range that Mises stress exceeds allowable stress is large, It has been through the components. Here is a weak link of the gate. The gate should be damaged from here first.There are several reasons lead to the stress of main beam web plate is very large. First of all, the web plate hole is too big. The ratio of opening area and the rest of the area is $36 \%$. Second, web height at both ends decrease too much.Finally, web height 
change at the hole edge width is too small. The following is the results of the model without hole.The maximum Mises stress of gate bottom main beam webs is 289.8MPa. It is much smaller than the original model.

According to the scene photos, the edge of main beam web plate hole indeed be pulled, forecast in agreement with the finite element results.

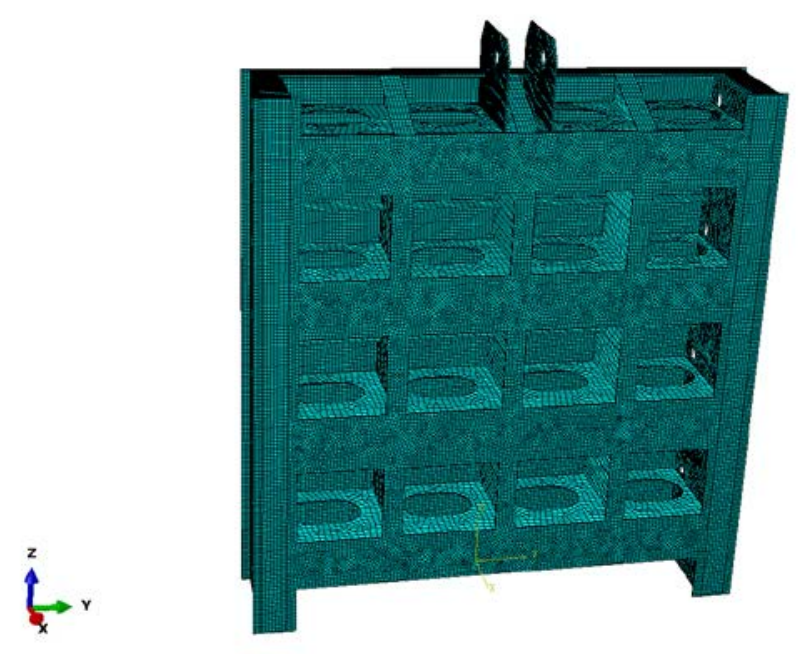

Fig.1 finite element model of gate

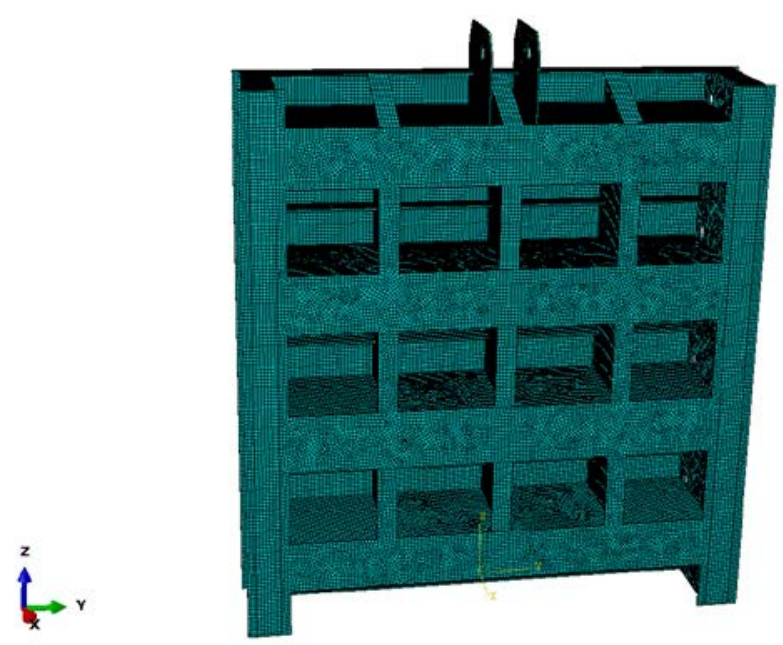

Fig.2 finite element model of gate without hole 


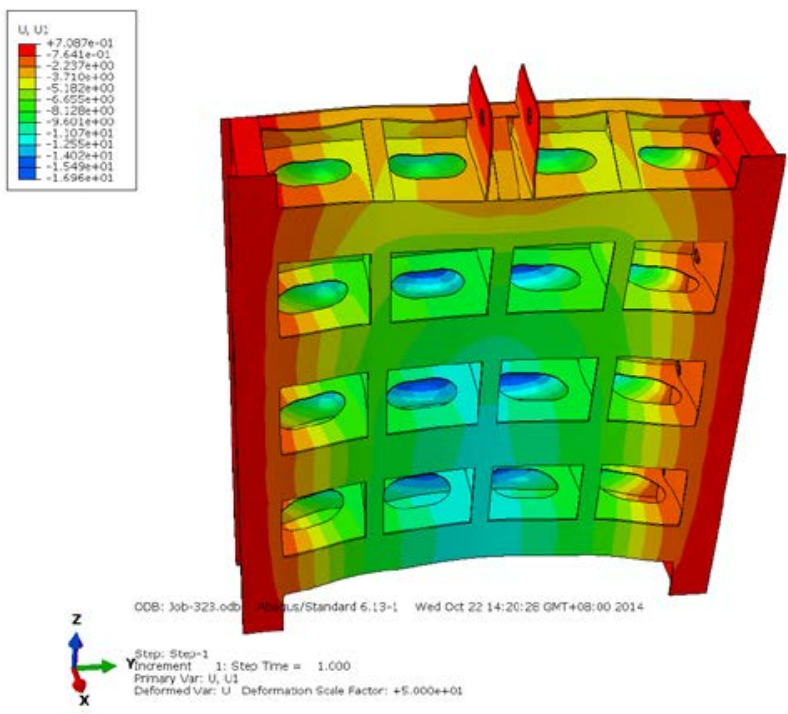

Fig.3 displacement of gate along the direction of flow
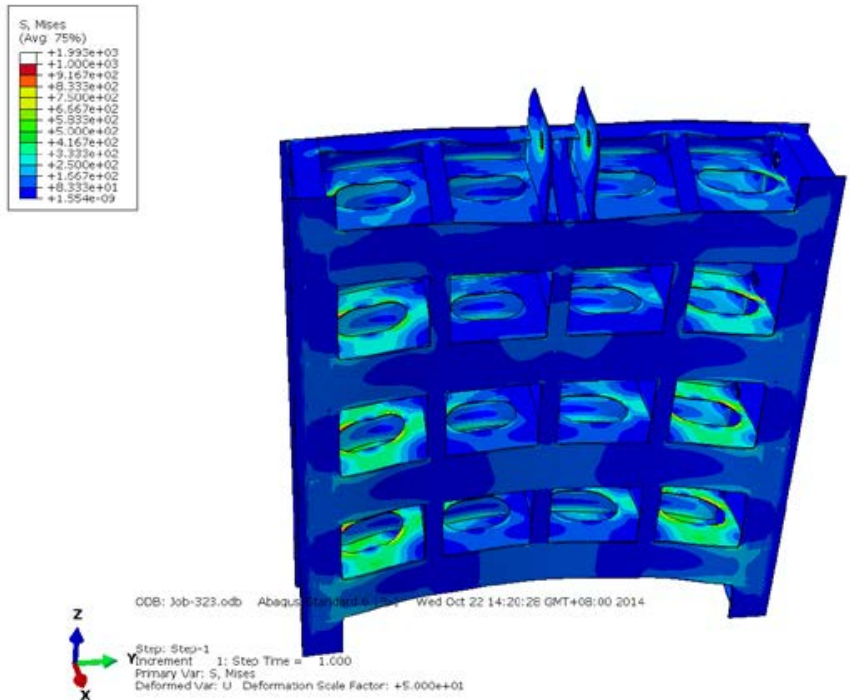

Fig.4 Mises stress of gate


Fig. 5 Mises stress of gate bottom main beam webs 

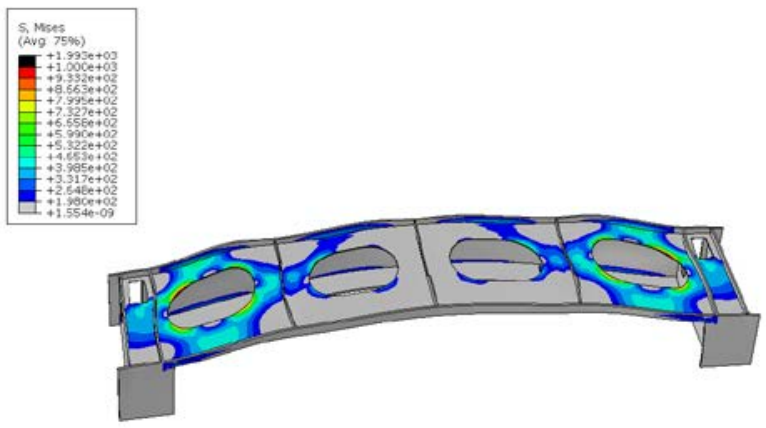

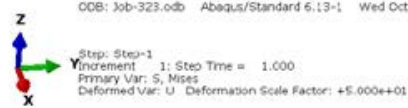

Fig.6 Mises stress of gate bottom main beam webs
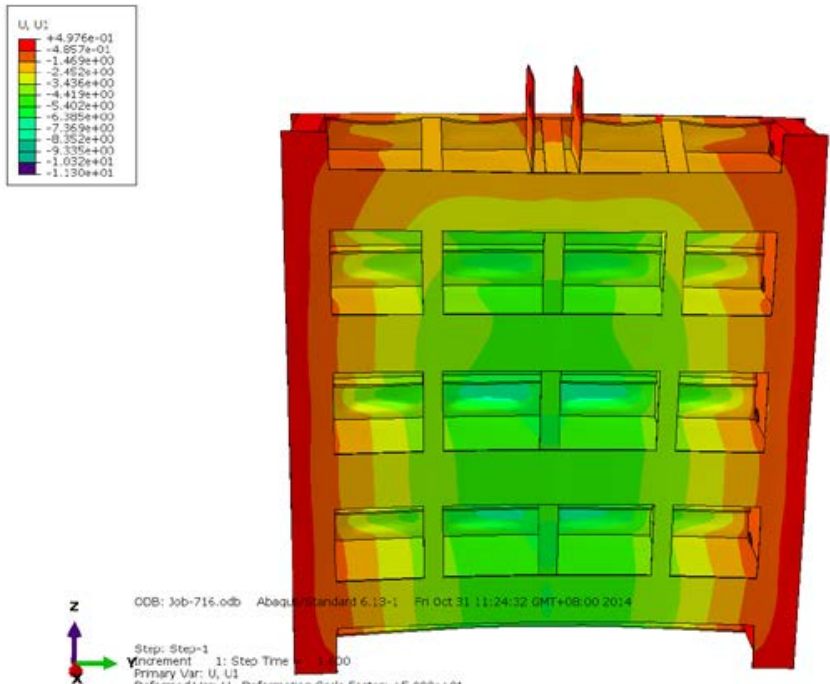

Fig.7 displacement of gate without hole along the direction of flow
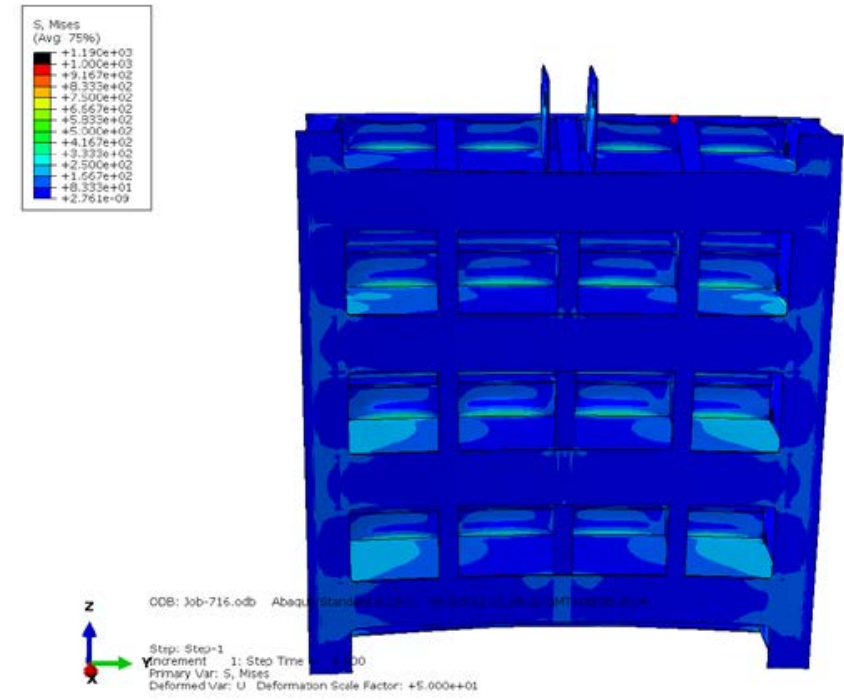

Fig.8 Mises stress of gate without hole 

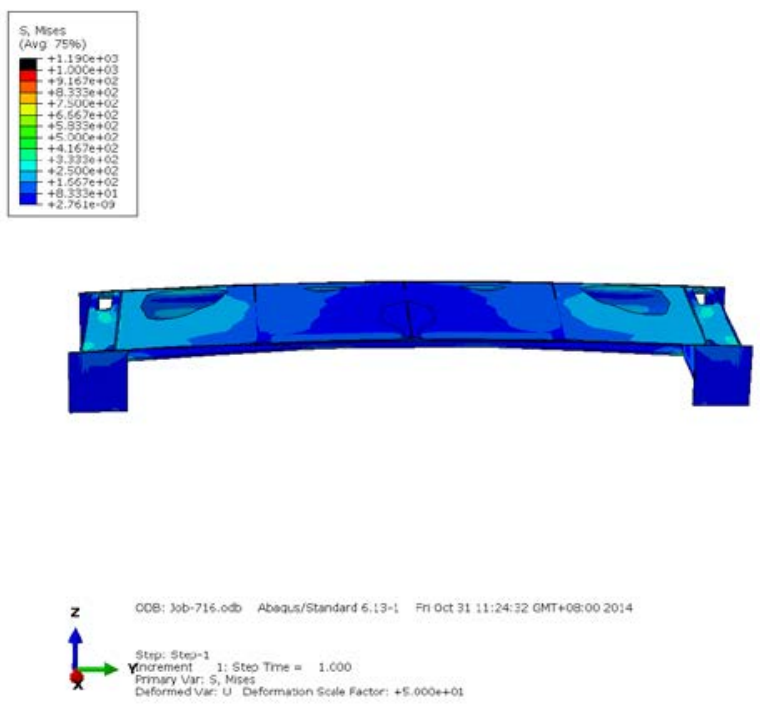

Fig.9 Mises stress of gate without hole bottom main beam webs

\section{Acknowledgements}

This work was financially supported by the National Natural Science Foundation of china (No. 51279071) and the Natural Science Foundation of Kunming University of Science and Technology (No.20149x16).

\section{References}

[1] Survey and design institute of northeast. Water Resources and Hydropower Engineering Steel Gate Design Specification. China Water Conservancy and Hydropower Press [M]. 1995

[2] Bingye Xu, Xinsheng Liu. Application of Elastic-Plastic Mechanics. Tsinghua University Press [M] . Beijing. 1995

[3] Youan Hu,Meng Wang. Hydraulic Steel Gate Numerical Simulation and Engineering Practice [M]. China Water Conservancy and Hydropower Press, 2010

[4] Riming Zhong. Bible of UG NX 8.0 [M]. Mechanical Industry Press, 2012

[5] Yiping Shi, Yurong Zhou. Using ABAQUS Finite Element Analysis of Example Explanation [M]. Mechanical Industry Press, 2006 